\title{
MARCAS: UM ATIVO IMPORTANTE E POR VEZES NEGLIGENCIADO
}

\section{BRANDS: AN IMPORTANT ASSET AND SOMETIMES NEGLECTED}

Wallace Gomes Moraes, Graduado em Administração (UPIS), Graduado em Tecnologia do Cooperativismo (UFV), Especialização em

Administração Rural (UFLA), Especialização em Gerenciamento de Resíduos da Agroindústria (UFLA), Professor do Curso de Administração da Faculdade Presidente Antônio Carlos de Teófilo Otoni, Brasil. E-mail: moraes.wallace@bol.com.br

Marcélia Aguiar Ferreira, Mestre em Administração Pública pela Universidade Federal dos Vales do Jequitinhonha e Mucuri, Especialista em Comunicação, Marketing e RH pela, Pós Graduada em Docência do Ensino Superior, Graduada em Administração, Coordenadora dos Cursos de

Administração e Ciências Contábeis e Coordenadora Adjunta do Curso de Sistemas de Informação da UNIPAC Teófilo Otoni, Brasil. E-mail: marceliaaguiar@hotmail.com

Thiago Ribeiro Oliveira, Mestre em Tecnologia, Ambiente e Sociedade, Especialista em Gestão Pública Municipal, Bacharel em Ciências Contábeis. Professor do curso de Contábeis da Faculdade Presidente Antônio Carlos de Teófilo Otoni, Brasil. E-mail: thiagoribeirounipac@gmail.com

Recebido: 10/11/2020 - Aceito: 27/11/2020

\section{Resumo}

A gestão dos ativos intangíveis, isto é, o processo que uma empresa utiliza para fazer o melhor uso destes de forma a contribuir de maneira efetiva na geração de valor leva a empresa a identificar aqueles que sejam mais relevantes para o negócio. A empresa precisa entender quais são os ativos que participam mais ativamente da geração de valor e priorizá-los, já que os diversos tipos de intangíveis, podem influenciar diferentemente nos diferentes tipos negócios. Cada um dos intangíveis deve ter diretrizes e estratégias e a empresa deve saber o que ela espera destes. A partir do momento que se tem os intangíveis chaves e a estratégia de cada um deles, se chega ao momento de desenhar o processo de gestão, gerenciando-os e tratando-os de forma integrada. Uma boa parte do que vale uma empresa é devido aos intangíveis, sendo muitas vezes até maior que o 
valor somado dos tangíveis. O ativo intangível tem dois papéis importantes: gerar valor e proteger valor. Dentre os intangíveis pode-se citar a marca que deve ser traduzida em uma série de iniciativas visando fortalecer seu posicionamento no mercado, criando um ambiente favorável a obter vantagens competitivas. Este ativo de grande importância, muitas vezes é negligenciado, gerando distorções que podem comprometer o empreendimento.

Palavras-chave: Ativos intangíveis. Geração de valor. Gestão de Marcas

\section{Abstract}

The management of intangible assets, that is, the process that a company uses to make the best use of them in order to contribute effectively to the generation of value, leads the company to identify those that are most relevant to the business. The company needs to understand which are the assets that participate more actively in the generation of value and prioritize them, since the different types of intangibles, can influence differently in the different types of business. Each of the intangibles must have guidelines and strategies and the company must know what it expects from them. From the moment that you have the key intangibles and the strategy of each of them, it is time to design the management process, managing and treating them in an integrated manner. A good part of what a company is worth is due to intangibles, often being even greater than the added value of tangibles. Intangible assets have two important roles: generating value and protecting value. Among the intangibles we can mention the brand that should be translated into a series of initiatives aimed at strengthening its position in the market, creating a favorable environment to obtain competitive advantages. This very important asset is often neglected, generating distortions that can compromise the enterprise.

Keywords: Intangible Assets. Value generation. Branding

\section{Introdução}

Ser dono do próprio negócio é um sonho de muitas pessoas. Montar uma empresa, construir um patrimônio, proteger uma invenção, ter uma marca exclusiva, são desejos em comum de todo empresário de sucesso. O problema é que durante esse percurso alguns gestores não se atentam para alguns detalhes que podem fazer a diferença no futuro da empresa.

Com a globalização da economia, as marcas vêm ganhando visibilidade, valor, e acima de tudo a conquista da confiança do empresário e, claro, do cliente. Proteger esse patrimônio tem sido uma preocupação cada vez mais premente. 
O que era tido pelo empresário como uma necessidade hoje é prioridade. Qualquer empresa ou pessoa física que utilize um nome para se comunicar com o mercado, pode e deve protegê-lo. Essa proteção lhe garantirá exclusividade na atividade a qual se dedica além de proibir que terceiros se apropriem sem autorização, usufruindo vantagens.

Neste contexto a marca constitui-se em um ativo intangível de grande importância e muitos empresários ainda não se deram conta disso. Embora, no início, ela seja apenas um nome, com o passar dos anos será justamente a marca que refletirá a reputação e os valores de um negócio, que com certeza terá grande valor.

\section{Revisão da literatura}

\subsection{Ativos}

Segundo (IUDÍCIBUS \& MARION, 2011, p. 15) os ativos são todos os bens e direitos de propriedade da empresa, avaliáveis em dinheiro, que representam benefícios presentes ou futuros para empresa.

Ainda segundo Marion (2004, p. 53) são os itens positivos do patrimônio; trazem benefícios, proporcionam ganho para a empresa. "

Assim sendo, dentro deste grande grupo contábil aparece os ativos intangíveis, que de acordo com (MARION, 2009, p. 218) não têm substância física e que, por serem abstratos, não podem ser tocados, palpados, mas podem ser comprovados.

De acordo com Hendriksen e Breda (2007, p. 388):

\footnotetext{
"A palavra intangível vem do latim tangere, ou "tocar". Os bens intangíveis, portanto, são bens que não podem ser tocados, porque não têm corpo. Mais formalmente, diz-se que os ativos intangíveis são incorpóreos (corpus = corpo). $"$
}

São considerados bens intangíveis pois são aqueles que não têm existência física. São exemplos de bens intangíveis: os direitos de exploração de serviços públicos mediante concessão ou permissão do Poder Público, marcas e patentes, direitos autorais adquiridos, softwares e o fundo de comércio adquirido. Entretanto, 
isso não exclui seu valor. Muitas empresas detêm patentes que são de extremo valor e de igual forma, possuem marcas que muitas vezes tem o valor maior de mercado, do que seus bens físicos.

Segundo Moraes (2019) os ativos intangíveis têm exercido um papel cada vez mais importante na criação de valor das empresas, especialmente porque são importantes fontes de vantagem competitiva. Tanto as marcas como as patentes representam um bem patrimonial, agrupado no grupo do ativo permanente e considerando sua essência é de fundamental importância gerenciá-los adequadamente para que possam contribuir para o alcance do maior objetivo financeiro da empresa, o de maximizar o retorno sobre o capital investido

Contabilmente, segundo (ALMEIDA, 2017, p. 138) a necessidade de definição de políticas e soluções financeiras que possam monetizar os ativos intangíveis tem demandado de governos e organizações o reconhecimento de que o esforço exige uma maneira aberta, transparente, justa e eficiente de lidar com a contabilização. Uma das dificuldades frequentes é a falta de mecanismos financeiros padronizados para avaliar os valores desses ativos.

Neste aspecto, ainda segundo (ALMEIDA, 2017) preciso ficar claro para investidores e outros públicos de interesse o quanto os intangíveis agregam de valor econômico para as empresas. Uma avaliação mais consistente e confiável dos intangíveis deve provocar uma transformação definitiva nos modelos de gestão empresarial, tornando-se cada vez mais uma tarefa relevante para membros do conselho e altos executivos.

\subsection{Marcas}

Muitas vezes o empreendedor ao abrir uma empresa não se preocupa com o registro da marca e acaba adiando esta decisão, que pode impactar seu empreendimento no futuro. Uma dessas decisões extremamente importantes diz respeito ao registro da própria marca, que deve ser feito logo após a criação do nome da empresa. Tanto as marcas como as patentes representam um bem patrimonial.

A palavra marca, segundo (GRACIOSO, 2010, p. 83) é de origem germânica e significa aplicar um sinal que identifica a propriedade. Assim sendo uma marca identifica a empresa ou o fabricante. Pode ser um nome, uma marca comercial, um logotipo ou outro símbolo. 
Marca é tudo o que se relaciona com a sua propagação, desde um mero uniforme e o logotipo estampado nele, até o impacto social que ela possa causar, como a Apple - mais uma vez - que revolucionou a Era da Informação.

O conceito da marca abrange tudo o que permeia os produtos e a empresa. Cria-se uma cultura corporativa. Todos os envolvidos com a empresa participam, do funcionário ao consumidor final. Ao contrário do que grande parte das pessoas tem em mente, a marca não se restringe apenas àqueles logotipos bonitos, como o da Apple, que é uma marca de exemplo absoluto.

\section{Segundo Las Casas (2010, p. 261):}

A marca é a identificação do produto. Assim como uma pessoa identificase pelo nome, sua aparência, sua personalidade, um produto identifica-se pela sua marca, sua embalagem e seu posicionamento. A identificação da marca é mais abrangente do que apenas um nome, uma vez que pode ser representada por um símbolo, desenho ou termo.

Assim, as marcas são, segundo o INPI (Instituto Nacional de Propriedade Industrial), "sinais visualmente perceptíveis". Elas devem ser percebidas facilmente para distinguir produto ou serviço. As marcas servem não apenas como forma de garantir um direito, mas principalmente em função do reconhecimento cada vez maior, de que a marca se constitui num importante ativo para as empresas.

A marca registrada garante ao seu proprietário o direito de uso exclusivo em todo o território nacional em seu ramo de atividade econômica. Ao mesmo tempo, sua percepção pelo consumidor pode resultar em agregação de valor aos produtos ou serviços por ela identificados. Ela quando bem gerenciada, ajuda a fidelizar o consumo, estabelecendo, assim, identidades duradouras.

Segundo Kotler (2000) muito além dos atributos que uma marca possui, existem outros fatores que os clientes estão mais interessados. O cliente busca por benefícios, pois características podem ser copiadas tornando algumas particularidades menos interessantes futuramente.

Ainda conforme Kotler (2000) tem-se a essência de uma marca em seus significados traduzidos através de sua personalidade, valores e cultura.

Para Kotler (2000, p. 426) a criação e gestão de marca é o problema principal na estratégia do produto. Por um lado, desenvolver um produto de marca requer um grande investimento de longo prazo, especialmente em propaganda, promoção 


\section{Revista Multidisciplinar do Nordeste Mineiro, 2020/02 ISSN 2178-6925}

e embalagem. Por outro lado, os fabricantes acabam aprendendo que o poder no mercado reside em construir nomes de próprias marcas.

Ainda conforme Kotler (2000, p. 430): Os distribuidores e varejistas querem nomes de marca porque as marcas facilitam a comercialização dos produtos, além de manter a produção em certos níveis de qualidade, fortalecendo as preferências do comprador, e ajudam a identificar os fornecedores. Os consumidores querem nomes de marca para ajudá-los a identificar diferenças de qualidade e comprar com mais eficiência.

"De fato, toda marca poderosa representa um grupo de clientes fiéis. Portanto, o bem fundamental que sustenta o patrimônio da marca é o valor do cliente. " (KOTLER, 2000, p. 428)

Tomazette (2018, p. 174), declara:

Para o empresário as marcas funcionam como meios de atrair clientela distinguindo os produtos ou serviços em relação aos dos seus concorrentes. Elas servem também para resguardar os interesses do consumidor em relação à qualidade ou proveniência de determinado produto ou serviço, ou seja, a marca é um referencial para o consumidor poder fazer suas escolhas. Em suma, a marca tem dupla finalidade: resguardar os direitos do titular e proteger os interesses do consumidor.

"Infelizmente, muitas empresas gerenciam mal seu maior ativo - suas marcas. Na busca de lucros sempre maiores, é fácil uma marca perder o seu foco. " (KOTLER, 2000, p. 428) Kotler (2000, p. 428):

Um nome de marca precisa ser cuidadosamente gerenciado para que seu valor patrimonial não se deprecie. Isso requer manter e melhorar a conscientização da marca, sua qualidade e sua funcionalidade percebidas e associações positivas a ela. Essas tarefas exigem investimento contínuo em P\&D, publicidade habilidosa e excelente atendimento ao varejista e ao consumidor.

\section{3- Registro das Marcas}

São registráveis como marca os sinais distintivos visualmente perceptíveis, não compreendidos nas proibições legais (art. 122 da Lei de Propriedade Industrial). Esta norma legal dispõe, que:

- a marca deve consistir em sinal visualmente perceptível; 
- os sinais visualmente perceptíveis devem revestir-se de identificação, para se prestarem a assinalar e distinguir produtos ou serviços dos demais, de procedência diversa;

- a marca pretendida não pode incidir em quaisquer proibições legais, seja em função da sua própria constituição, do seu caráter de laicidade ou da sua condição de disponibilidade.

Existem três tipos de marcas: a nominativa, a figurativa e a mista. A marca nominativa é aquela constituída por uma ou mais palavras no sentido amplo do alfabeto romano, compreendendo, também, os neologismos e as combinações de letras e/ou algarismos romanos e/ou arábicos. A marca figurativa é aquela constituída por desenho, figura ou qualquer forma estilizada de letra e número, isoladamente. A marca mista é aquela constituída pela combinação de elementos nominativos e figurativos ou de elementos nominativos, cuja grafia se apresente de forma estilizada.

O registro de uma marca garante a propriedade e o uso exclusivo em todo o território nacional, por dez anos, necessitando que o titular mantenha em uso e prorrogá-la de dez em dez anos. Por outro lado, o registro da marca extingue-se pela expiração do prazo de vigência, pela renúncia (abandono voluntário do titular ou pelo representante legal), pela caducidade (falta de uso da marca) ou pela inobservância do disposto no art. 217 da LPI.

A marca também pode ter seu registro requerido por pessoa física desde que comprove a atividade exercida, através de documento comprobatório, expedido pelo órgão competente, onde

Segundo Jabur \& Santos (2007, p. 56) “o texto constitucional preceitua e determina o teor da lei ordinária, estipulando as condições básicas para a concessão de patentes industriais, marcas e outros direitos. "

O texto constitucional, em seu art. $5^{\circ}$, inciso XXIX, dispõe:

XXIX - a lei assegurará aos autores de inventos industriais privilégio temporário para sua utilização, bem como proteção às criações industriais, à propriedade das marcas, aos nomes de empresas e a outros signos distintivos, tendo em vista o interesse social e o desenvolvimento tecnológico e econômico do País;

O registro de uma marca garante a propriedade e o uso exclusivo em todo o território nacional, por dez anos, necessitando que o titular mantenha em uso e 
prorrogá-la de dez em dez anos. Por outro lado, o registro da marca extingue-se pela expiração do prazo de vigência, pela renúncia (abandono voluntário do titular ou pelo representante legal), pela caducidade (falta de uso da marca) ou pela inobservância do disposto no art. 217 da LPI.

De acordo com o artigo $133^{\circ}$ da Lei n. ${ }^{\circ}$ 9.279/96, "o registro da marca vigorará pelo prazo de 10 (dez) anos, contados da data da concessão do registro, prorrogável por períodos iguais e sucessivos. "Quem registra a marca tem direito de utilizá-la exclusivamente, não se permite que ninguém use a marca sem a sua autorização. (TOMAZETTE, 2018, p. 191) "

Contudo, segundo (Moraes, 2019) antes de sair fazendo logomarca, identidade visual (folders, panfletos, etc) e outras providências, o primeiro passo para registrar uma marca, é realizar uma busca prévia verificando se a marca permite o registro e se já existe alguma marca depositada ou registrada na classe pretendida, por outro.

\section{4- Valoração Monetária das marcas}

As marcas valem tanto que usualmente são contratadas consultorias especializadas para estimar o valor de marca das empresas. Historicamente uma das primeiras empresas que avaliou o valor de uma marca foi a Interbrand, a partir de uma metodologia desenvolvida em 1988. Atualmente, em função da grande demanda, estimulada pelo fato da marca ter se tornado um diferencial, existe um grande número de empresas que prestam esse tipo de serviço.

A valoração de uma marca pode envolver diferentes fórmulas e metodologias, utilizadas por empresas especializadas em mensurar o valor. Embora haja uma grande diversidade de metodologias, entende-se que o valor das marcas está relacionado às duas variáveis de criação de valor analisadas: o valor de mercado sobre valor contábil e o Q de Tobin).

O q de Tobin representa a razão entre o valor da firma e o valor de reposição dos ativos das empresas. Desenvolvido por James Tobin, em 1969, o q de Tobin pode ser definido segundo seu autor (TOBIN, 1969) como o valor de mercado das ações ou capital próprio da empresa, acrescido do valor de mercado das dívidas ou capital de terceiros empregado. 
Segundo, Pacheco (2005), o "Q" é a proporção entre o valor de mercado da empresa (preços de mercado versus número de ações), comumente mensurado com o objetivo de identificar a verdadeira possibilidade de capitalização da empresa e o custo de reposição de seus ativos, entre eles, destaca-se os equipamentos, máquinas, edifícios, entre outros ativos relacionados com o processo de produção e de administração.

Embora bastante utilizado nos EUA, o mercado de capitais brasileiro prefere outras métricas como o $\mathrm{P} / \mathrm{L}$ (preço por lucro), o FV/Ebtida (valor da firma pela geração de caixa operacional simplificada) e o fluxo de caixa descontado.

\section{5 - Branding (Gestão de Marcas)}

Muitas vezes confunde-se erroneamente que Marketing e Branding são a mesma coisa. O Marketing é a área estratégica e operacional de uma organização que trata de questões que interligam a empresa, seus funcionários e seu mercado de atuação.

A despeito do que muitos apregoam que o marketing tem por objetivo fazer com que as pessoas comprem aquilo que não querem, no momento que não precisam e na ocasião que não podem, não é bem verdade. Mesmo com a maciça publicidade que os produtos são apregoados, elevando o grau de consumismo, através da criação de uma necessidade artificial, o consumidor sabe bem o que quer e porque quer.

Para Kotler e Armstrong (2005) o marketing é uma filosofia que requer que os profissionais da área mercadológica levem em conta três fatores na hora de definir sua política de mercado, a empresa (lucros), os consumidores (satisfação dos desejos) e a sociedade (bem-estar da humanidade).

Ainda segundo o mesmo autor, a função do marketing, mais do que qualquer outra nos negócios, é lidar com os clientes. Entender, criar, comunicar, e proporcionar ao cliente a satisfação plena. De nada adianta vender um produto hoje com base em apelos momentâneos e pontuais para depois de um certo tempo não atender mais os anseios do consumidor. Vender bem para poder vender sempre. Manter um mercado consistente, apesar de ser mais difícil, é melhor do que a buscar mercados voláteis e sem fidelidade. 
Por outro lado, o Branding (Gestão de Marcas) é algo com mais complexo que permeia pelas percepções tangíveis e intangíveis e, pessoais de cada grupo ou indivíduo, ou seja, é a cultura gerada pelada empresa. Sendo assim, Branding é uma prática que consiste em utilizar das práticas de gestão de todas as áreas da empresa para influenciar positivamente a relação entre a própria empresa e seus públicos.

O Branding consiste em conhecer detalhes na percepção que os consumidores em relação a uma marca. $O$ fato é que os consumidores atualmente querem criar vínculos emocionais com as marcas, ou seja, não querem lidar com empresas e sim com as pessoas que a operam. Isto ocorre motivado pelo avanço das redes sociais e a internet fazendo com que as pessoas estão se tornando mais informadas e buscando se relacionar com profundidade com as marcas.

É, pois, um processo mais complexo pois envolve variáveis como a qualidade operacional dos produtos, o design, o atendimento, a adaptabilidade com o produto, a tecnologia no sentido de gerar o "Brand Equity", que é o valor agregado pelo cliente, o " plus" "algo mais".

É claro que, para alcançar esse patamar, a empresa precisa ser competente em outros aspectos, já que o branding necessita de todas as áreas da empresa no sentido de proporcionar a melhor experiência ao consumidor, mas não na primeira ocasião e sim em todas, como forma de fidelização.

Em um mercado altamente competitivo o que vai fazer a diferença vai ser sem dúvida o poder da marca. A marca precisa evoluir, acompanhando as demandas do seu público, que sabidamente tem suas necessidades e preferências em constantes mudanças, seja por questões econômicas, sociais e até mesmo consciência ambiental.

Saber o produto que o consumidor deseja é de certa forma ser coparticipe de sua vida. É entender suas necessidades, seus anseios e seus critérios de valoração. Entender este mundo pessoal, dentro do mercado, extrapolando e fortalecendo um ideário coletivo significa a plena aceitação do produto. Seja por motivos fisiológicos, racionais, emocionais ou seletivos o consumidor está sempre ávido a consumir. Para ele, torna-se muito mais traumático querer consumir um produto e não ter do que ter este produto e não desejar. O clima de impotência perante o mercado é muito mais arrasador e frustrante para o consumidor. 
Segundo (KOTLER, 2000, p. 430) o uso de uma marca dá à empresa diversas vantagens:

- Um nome de marca ajuda a empresa a processar pedidos e solucionar problemas.

- O nome de marca da empresa oferece proteção legal aos aspectos exclusivos do produto.

- O uso de marca oferece à empresa a oportunidade de atrair um grupo de clientes fiel e lucrativo. A fidelidade à marca fornece à empresa alguma proteção em relação à concorrência.

- O uso de marca ajuda a empresa a segmentar seus mercados.

- As marcas fortes constroem a imagem corporativa, tornando mais fácil lançar novas marcas e ganhar a aceitação dos distribuidores e consumidores.

\section{Considerações finais}

De acordo com Moraes (2019) a marca é um dos principais ativos de uma empresa e muitos empresários ainda não se deram conta disso. Embora, no início, ela seja apenas um nome, com o passar dos anos é justamente a marca que refletirá a reputação e os valores de um negócio, que com certeza terá grande valor.

Os intangíveis ganharam muita importância porque o mundo dos negócios mudou, saindo de uma era industrial para uma era do conhecimento. Enquanto na era industrial o que tinha importância eram as máquinas, ou seja, o que se tinha de tangível, hoje, na era do conhecimento, o que se tem valor, é o que se é produzido pela mente humana.

As marcas associadas ao branding têm exercido um papel cada vez mais importante na criação de valor das empresas, especialmente porque são importantes fontes de vantagem competitiva. O branding, ou gestão de marcas, é uma área de suma importância no âmbito empresarial embora não seja raro que ele acaba sendo negligenciado por falta de visão em perceber que a marca tem o potencial de ser o patrimônio mais valioso de uma empresa.

Neste contexto de um mundo mais complexo as empresas devem se preocupar em gerar valores para seus públicos, pois não é mais o valor monetário somente a ser levado em conta, mas também o social, o ambiental, comportamental uma vez que os consumidores quase sempre levam em conta outras variáveis para concluir a decisão de compra, como o atendimento, a aparência física, facilidade de compra, informações sobre o produto, dentre várias. 
É de fundamental importância gerenciá-los adequadamente para que possam contribuir para o alcance do maior objetivo financeiro da empresa, o de maximizar o retorno sobre o capital investido.

Portanto fica claro que as marcas são reconhecidamente um dos principais geradores de riqueza das organizações. O mundo mudou totalmente. E hoje estamos na era do conhecimento!

\section{Referências}

ALMEIDA, Ana Luísa C. (2017). Gestão integrada de ativos intangíveis: cultura, liderança, confiança, marca e reprodução. São Paulo: Saraiva.

BRASIL. (1988). Constituição Federal(1988). Constituição da República Federativa do Brasil Disponível em:<http://www.planalto.gov.br/ccivil_03/constituicao/constituicao.htm>

BRASIL. (1996). Lei $n$. 9.279 de 14 de maio de 1996. Regula os direitos e obrigações relativos à propriedade industrial.Disponível em: <http://www.planalto.gov.br/ccivil_03/leis/19279.htm>

GRACIOSO, Francisco, (2010). Marketing Estratégico. São Paulo: Atlas.

HENDRIKSEN, E. S., \& BREDA, M. F. (2007). Teoria da contabilidade. São Paulo: Atlas.

INPI. Instituto Nacional da Propriedade Industrial, Brasília-DF, Disponível em: < http://www.inpi.gov.br >

IUDíCIBUS, S. d. (2010). Contabilidade comercial. São Paulo: Atlas.

IUDÍCIBUS, S. d., \& MARION, J. C. (2011). Curso de contabilidade para não contadores. São Paulo: Atlas.

JABUR, W. P., \& SANTOS, M. J. (2007). Criações Industriais, Segredos de Negócio e Concorrência Desleal. São Paulo: Saraiva.

KOTLER, Philip. (2000). Administração de Marketing. São Paulo: Pearson Prentice Hall.

LAS CASAS, A. L. (2010). Administração de Marketing. São Paulo: Atlas.

MARION, José Carlos (2009). Contabilidade básica. São Paulo: Atlas. 
MORAES, Wallace Gomes. (2019). Administração de recursos materiais e patrimoniais: um enfoque prático. São Paulo: Ixtlan.

PACHECO, V. A mensuração e divulgação do capital intelectual como instrumento de apropriação de inovações tecnológicas na gestão dos negócios. Curitiba: Conselho Regional de Contabilidade do Paraná, 2005.

TOMAZETTE, M. (2018). Curso de direito empresarial: teoria geral e direito societário. São Paulo: Saraiva educação. 